\title{
Крепс T.B. \\ Использование элементов технологии концентрированного обучения в гуманитарном колледже
}

ФГБОУ ВО Кубанский государственный университет физической культуры, спорта и туризма

(Россия, Краснодар)

doi: $10.18411 / l j-02-2021-141$

idsp: ljournal-02-2021-141

\section{Аннотация}

В статье рассмотрены модель «погружение» и модель интенсивного обучения с применением суггестивного воздействия, как основные модели организации концентрированного обучения. Отмечено, что элементы интенсивного обучения, предполагающего суггестивное воздействие, применимы в системе среднего профессионального и высшего образования без сжатия учебного материала в укрупненные содержательные единицы. Раскрывается представление о проектировании содержания элементов концентрированного обучения в средних группах обучающихся в гуманитарном колледже с использованием интерактивных методов обучения.

Ключевые слова: концентрированное обучение, технология погружения как модель концентрированного обучения, модель интенсивного обучения с применением суггестивного воздействия, коллективный способ обучения, интерактивные методы обучения, мозговой штурм

\section{Abstract}

The article considers the "immersion" model and the model of intensive training with the use of suggestive influence as the main models of the organization of concentrated training. It is noted that the elements of intensive training, involving a suggestive effect, are applicable in the system of secondary vocational and higher education without compressing the educational material into enlarged content units. The article reveals the idea of designing the content of the elements of concentrated learning in the middle groups of students in the humanities college using interactive teaching methods.

Keywords: concentrated learning, immersion technology as a model of concentrated learning, intensive learning model with the use of suggestive influence, collective learning method, interactive learning methods, brainstorming

В условиях пандемии большая часть высшего и среднего профессионального образования уходит в онлайн и в виртуальную среду, что подразумевает поиск эффективных педагогических технологий, позволяющих организовать совместную деятельность преподавателя и студентов, а также развитие и реализацию личностного потенциала студента.

Одной из таких технологий является технология концентрированного обучения. Это процесс, предполагающий усвоение обучающимися большего количества учебной информации без увеличения учебного времени за счет ее систематизации, обобщения и структурирования. Также применяется иной, отличительный от традиционного, временной режим занятий. К основным моделям концентрированного обучения отнесены «погружение» М.П. Щетинина [5] и суггестопедия Г.К. Лозанова [2]. Поэтому выделяем два подхода к модели концентрированного обучения:

— модель «погружение», как длительное (от нескольких часов до нескольких дней) специально организованное занятие по одному или нескольким предметам. Использовать такой алгоритма достаточно сложно, поскольку требуется определенное расписание для групп 
обучающихся, когда занятия «основного» предмета перемежаются занятиями образно-эмоциональной сферы, а сами «погружения» повторяются через определенный промежуток времени. Технология заключается в такой организации учебного процесса, при которой внимание педагогов и обучающихся сосредоточивается на более глубоком изучении каждого предмета за счет объединения занятий в блоки, сокращения числа параллельно изучаемых дисциплин в течение учебного дня, недели.

- метод интенсивного обучения, предполагающий суггестивное воздействие. Его элементы применимы в системе среднего профессионального и высшего образования, так как использование суггестивного воздействия подразумевает создание ситуации внутренней уверенности за счет устранения психологического блока боязни сделать ошибку $[1,4]$.

Суггестивное воздействие основано на принципах снижения напряженности, единства осознания и неосознания, взаимосвязи. Реализуются они с помощь дидактических и психологических средств. Обязательно присутствует артистизм, что вносит в занятие элемент режиссированного мероприятия, когда не только преподаватель, но и обучающиеся ведут себя уверенно и, соответственно, принимают активное участие. При этом внутренняя настроенность на обучение у студентов связанна с доброжелательным отношением к предмету, когда нет страха сделать ошибку. Для этого, прежде всего, необходимо установить взаимосвязь студентов друг с другом и с преподавателем. Подход стал популярным в связи с изучением иностранных языков, поскольку позволяет «погрузиться» в иностранную среду на занятиях. Г.К. Лозанов [3] отмечает эффективность в малых группах.

Для применения интенсивного обучения в средних группах можно использовать, как оптимальный вариант организации, коллективный способ. Тогда при концентрированном обучении предполагается взаимодействие обучающихся в динамических парах, когда каждый студент выполняет роль то обучаемого, то обучающего. То есть студент выходит на продуктивный уровень, объясняя информацию другому.

Коллективный способ обучения способствует тому, что студент не только готовится к выполнению задания. В рамках работы он берет на себя роль объяснить материал другому обучающемуся, при смене ролей выслушать объяснения или выполнить данное «коллегой» задание. Динамика на занятии позволяет не только менять роли, но и повторно осуществить действия идентичные предыдущим, когда студент получает или самостоятельно находит нового партнера. Таким образом, задания делегируются и разделяются в соответствии со способностями обучающихся, осуществляется непрерывная передача знаний, основанная на взаимопомощи и настроенности на обучение.

Учебная деятельность делится на три этапа, подразумевающих систематизацию знаний, структурирование и подачу нового материала при помощи компактных структурно-логических схем.

Первый этап - это начало работы. Преподаватель объясняет цель работы, способствует организации динамических групп и раздает студентам маршрутные листы, в которые нужно вносить информацию о выполненных заданиях. При концентрированном обучении в динамических парах этап начинается с самостоятельного знакомства студента, получившего роль обучающего, с новым материалом.

На втором этапе начинается работа по объяснению и выполнению задания. Динамическая группа может насчитывать несколько вариационных пар, так, например, работа в парных четверках будет осуществляться в четыре такта, так как обучающиеся 
по окончании работы в паре каждый раз меняются карточками, составляющими маршрутный лист.

Третий этап основан на уточняющей, корректирующей работе и рефлексии. В маршрутных листах фиксируется итоговый материал. Преподаватель проводит совместный со студентами анализ.

Концентрированное обучение невозможно без использования интерактивных методов обучения. Одним из таких методов является интеллектуальная игра, позволяющая вовлечь всех обучающихся в процесс, стимулировать к овладению знаниями, умениями, навыками и самообразованию.

Построение и структура занятия с методом применения интеллектуальной игры состоит, как и типовое занятие, из трех этапов.

Вводный - организация участников, их мотивация. Таким образом, формулируется цель и задачи всего занятия или задания. Желательны разминочные задания для повторения пройденного или постановки проблемы для дальнейшего изучения нового материала. За счет суггестивного воздействия на вводном этапе создается ситуация успеха и внутренней уверенности обучающихся, что способствует эффективному переходу от простого сложного. На вводном этапе происходит подготовка обучающихся к проведению основной интеллектуальной игры - это и мотивационная составляющая, и целеполагание.

Основной этап - это техника взятия вопроса для выполнения задания. Для работы с группой студентов широко применим интерактивный метод - мозговой штурм, направленный на стимулирование творческой активности обучающихся. Участники высказывают свои мнения по решению заданий, при этом версии не подвергаются критики, чтобы даже самые застенчивые обучающиеся могли себя проявить. Однако, обязательна экспертная оценка, предполагающая распознавание ответов участников в целях выбора вероятных и верных вариантов решений. Сами участники интеллектуальной игры и берут на себя экспертную роль. При методе мозговой штурм большинство решений заданий дуальные, когда помимо авторского ответа, существуют и другие варианты, полностью соответствующие условиям, сформулированным в задание.

В структуре правильно организованного «мозгового штурма» включены такие элементы, как постановка проблемы, генерация идей участниками, их дальнейшая группировка и отбор с помощью экспертной оценки, заключительный анализ и оценка выбранных идей решения задания. Следует также обращать внимание на то, как обучающиеся сидят в аудитории. По возможности неуверенных и тихих обучающихся следует посадить ближе к участнику, записывающему варианты решения задания, эту роль в малой группе может взять на себя преподаватель. Оптимальная методика проведения мозгового штурма предполагает, что участники сидят небольшим полукругом на равном расстоянии у доски, на которую записываются варианты решения.

Завершающий этап связан с рефлексией. Устанавливается обратная связь, когда обучающиеся сообщают, что нового они узнали на занятие, что было интересно, а что вызвало трудности.

Методическая основа проектирования концентрированного обучения базируется на определении занятия в режиме погружения как формы организации процесса обучения; следовательно, при планировании и проведении подобного занятия, с одной стороны, удовлетворяются все требования дидактики, с другой стороны - учитывается специфика организации процесса концентрированного обучения. Структура занятия в режиме интенсивного обучения предполагает при изучении тем дисциплины различные варианты их группировки.

В исследовании приняли участие 46 обучающихся двух групп первого курса Гуманитарного колледжа Кубанского государственного университета физической 
культуры, спорта и туризма. В рамках изучения темы «Экологическое образование и просвещение» факультатива «Общая экология и природопользование» учебный материал был поделен на четыре раздела, каждый продолжительностью два академических часа (таблица 1). Начиная со второго занятия, раздел 2. «Педагогические технологии в экологическом образовании», применялись элементы технологии концентрированного обучения, а именно интенсивное обучение с использованием интерактивных методов.

Таблийа 1.

План тематического раздела по факультативу «Общая экология и природопользование» с применением метода интенсивного обучения

\begin{tabular}{|l|l|}
\hline \multicolumn{1}{|c|}{ Раздел } & \multicolumn{1}{c|}{ Содержание } \\
\hline $\begin{array}{l}\text { 1. Концепции экологического образования и } \\
\text { воспитания }\end{array}$ & $\begin{array}{l}\text { Лекция. Выполнение обучающимися контрольной } \\
\text { работы. Проверка по предложенным педагогом } \\
\text { эталонным ответам с обсуждением и } \\
\text { последующим оцениванием работы. }\end{array}$ \\
\hline $\begin{array}{l}\text { 2. Педагогические технологии в экологическом } \\
\text { образовании }\end{array}$ & $\begin{array}{l}\text { Самопогружение - самостоятельная работа } \\
\text { обучающихя по заданному плану в } \\
\text { динамических парах. Преподаватель работает в } \\
\text { режиме консультации. }\end{array}$ \\
\hline $\begin{array}{l}\text { 3. Преемственность системы непрерывного } \\
\text { экологического образования }\end{array}$ & $\begin{array}{l}\text { Практическое занятие - интерактивный метод } \\
\text { «мозговой штурм», как форма интеллектуальной } \\
\text { игры }\end{array}$ \\
\hline 4. Обобщение & $\begin{array}{l}\text { Зачет - выполнение обучающимися контрольной } \\
\text { работы в парных четверках с эталонными и } \\
\text { дуальными ответами. Контроль в виде } \\
\text { взаимопроверки с обсуждением и последующим } \\
\text { оцениванием работы. }\end{array}$ \\
\hline
\end{tabular}

Сравнение показателей успеваемости обучающихся до и после эксперимента по применению метода интенсивного обучения представлено на рисунке 1.

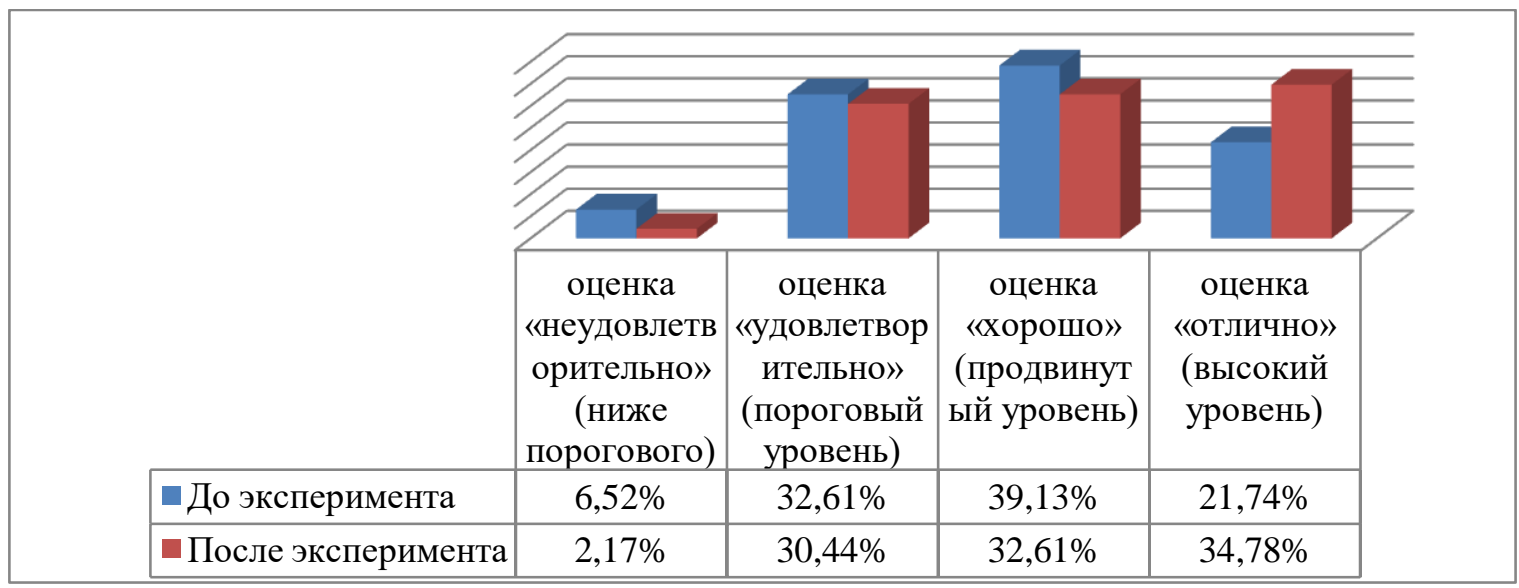

Рисунок 1. Сравнение показателей успеваемости обучающихся Гуманитарного колледжа по факультативу «Общая экология и природопользование» за экспериментальньй период

В ходе эксперимента показатель успеваемости по факультативу изменился следующим образом: количество обучающихся с оценкой «неудовлетворительно» (уровень ниже порогового) уменьшилось с трех обучающихся до одного (с $6.52 \%$ до $2.17 \%)$. Также уменьшилось число обучающихся с оценкой «удовлетворительно» (пороговый уровень) на одного, с оценкой «хорошо» (продвинутый уровень) до эксперимента было 18 обучающихся, после эксперимента - 15 обучающихся. С оценкой «отлично» (высокий уровень) - увеличилось более чем на 13\%, до начала эксперимента высокие уровень освоения показывали 10 обучающихся из 46, после эксперимента - 16 обучающихся. 
Показатель успеваемости за экспериментальный период дал положительную динамику. Анализ результатов показывает, что у большинства обучающихся после эксперимента по использованию элементов технологии концентрированного обучения при коллективном обучении преобладает продвинутый и высокий уровни.

Применение элементов технологии концентрированного обучения в гуманитарном колледже позволяет внедрить многообразие взаимодополняющих форм учебной деятельности, что обеспечивает восприятие и усвоение обучающимися блоков изучаемого материала. Эффект суггестивного воздействия обеспечивает оптимизацию сроков освоения преподаваемого материала, благоприятно влияет на мотивацию обучающихся, их внутреннюю настроенность на обучение, длительное взаимодействие друг с другом, с преподавателем в процессе обучения. Суть здоровьесберегающих технологий концентрированного обучения заключается в снижении усталости, эмоциональном и физическом комфорте.

$$
* * *
$$

1. Лозанов Г.К. Суггестология и суггестопедия. София: Наука и искусство. 1981. 124 c.

2. Лозанов Г.К. Сущность, история и экспериментальные перспективы суггестопедической системы при обучении иностранным языкам // Методы интенсивного обучения иностранным языкам. Вып. 3. М.: МГПИИЯ, 1977.

3. Малахина М.А. Использование технологии концентрированного обучения в образовательном процессе колледжа // Новая наука: Опыт, традиции, инновации. 2016. № 4-2 (77). С. 63-65.

4. Щетинин М.П. Погружение // Учительская газета. 1987. С. 3.

\section{Роббек М.К., Кривошеева Е.И. \\ Адекватность передачи текстов железнодорожной тематики с япон-ского на русский язык}

Тихоокеанский государственный университет (Россия, Хабаровск)

doi: 10.18411/lj-02-2021-142

idsp: ljournal-02-2021-142

\section{Аннотация}

В статье анализируются лексические и грамматические особенности текстов железнодорожной тематики в японском языке и рассматриваются варианты их адекватной передачи на русский язык. Выявляются основные способы терминообразования в указанной сфере в японском языке с целью их функциональной реализации в русском языке.

Ключевые слова: железнодорожный, японский язык, перевод, терминология, адекватность.

\section{Abstract}

The article analyzes lexical and grammatical difficulties in translation of articles related to the railway field from Japanese into Russian, and suggests ways of their adequate solution. The main methods of term formation of the studied area in the Japanese language are identified and the methods of their functional implementation in Russian are considered.

Key words: railway, Japanese, translation, terminology, adequacy.

Япония является важным соседом и партнером России, с которым страна нацелена укреплять обоюдовыгодное взаимодействие в научно-технической, гуманитарной и других областях. Не исключением является и сотрудничество в сфере железнодорожного сообщения и оптимизации логистических путей.

Актуальность статьи обусловлена тем, что на данный момент имеется целый ряд направлений экономического взаимодействия между Японией и Россией, которые 